\title{
Activation of External Social Capital of Heterogeneous Entrepreneurial Team Based on SNA
}

\author{
Hong Zhang ${ }^{1, *}$ \\ School of Economics and Management \\ Zhejiang Sci-Tech University \\ Hangzhou, China \\ e-mail: zhh96941@zju.edu.cn \\ * Corresponding Author
}

\begin{abstract}
To explore the activation mechanism of external social capital of entrepreneurial team, and improve the entrepreneurial success rate. We used case research to investigate three typical entrepreneurial teams, obtained data by tracking survey, and then used SNA method visually analyzed entrepreneurial teams' network characteristics and evolution rules. Our results show that in the start-up stage, strong ties of team members are more effective than weak ties on the activation of the external social capital. With the deepening of the entrepreneurial process, the weak ties are becoming more effective on the activation of external social capital. Furthermore, personal social networks sharing and mastering more structural holes are favor for the acquisition and integration of external social capital.
\end{abstract}

Keywords-entrepreneurial team; external social capital; heterogeneity; social network analysis; activation

\section{INTRODUCTION}

Entrepreneurship can promote the economic and social development, it is one of the most frequent words in the 2015 government work report of China's NPC \&CPPCC, 'mass entrepreneurship' has become the focus of public opinion. Existing research indicated that entrepreneurial forms have changed from individual entrepreneurship to team entrepreneurship. The achievements and success rate of team entrepreneurship are better than individual entrepreneurship (Francis \& Sandberg, 2000).

China is widely considered to be a relational society, relationship is very important to entrepreneurial team, and it plays an important role in business activities (Tanetal, 2008). Based on the national conditions of relational society, this paper mainly explores the mechanism and feasible path of the external social capital of the team through the track survey of three heterogeneous entrepreneurial teams, uses social network analysis method to visualize the characteristics and evolution law of the entrepreneurial network, and on this basis, analyses heterogeneous entrepreneurial team how to activate external social capital. Accordingly, the results provide valuable theoretical reference for entrepreneurial team to integrate and utilize external resources.

\section{LITERATURE REVIEW AND PROPOSITIONS}

A. The strength of team members' network relationship and the activation of external social capital

Granovetter (1973) proposed the weak ties superiority, considered the weak ties are effective bridge to transmit information in social networks. Zhou Dongmei\&Lu Ruoyu (2011) argued that in entrepreneurial network, members with strong relationships are very well known to each other, the internal trust may be more conducive to entrepreneurs to get venture resources. With the development of research, more scholars emphasize the difference functions of strong and weak ties in entrepreneurial networks. Bian Yanjie (2011) argued that weak ties have a higher probability of mobilizing information resources, strong ties have a higher probability of mobilizing human resources, and the strong ties have a greater advantage to mobilize mixed resources of information and human feelings. Under China's national conditions of relational society, strong ties are more conducive to get through the connections and expand the external social networks in the start-up stage of entrepreneurship. Zuo Jingjing et al. (2013) argued strong ties are the most important under China's special social and cultural background, the higher the relationship strength of entrepreneurs, the more resources they will obtain from the social network. Consequently, we proposed proposition 1:

Strong ties can bring social capital that can be used directly by heterogeneous entrepreneurial team in the initial stage, weak ties are conducive to expand external social network and activate external social capital.

\section{B. Entrepreneurial team member's network structural} hole and the activation of external social capital

For the initial entrepreneurial team, even if the members of the entrepreneurial team have a wide range of social networks, but if their connections are overlapping, this homogeneous network will not increase the social capital (Burt, 1992). Nevertheless, the structural hole of the entrepreneurial team can optimize the path to obtain external social resources. The structural hole theory was 
presented by Ronald Burt, it emphasized the weak ties have an important influence on social capital, the weak ties in the network can bring valuable information for the doers, provide the way to expand the social network and obtain social capital for doers. At the same time, the structural hole theory provides a clear theoretical guidance for the entrepreneurial team to optimize the relationship network (Batjargal, Hitt, Tsui et al., 2013). Through connecting members with different information and background, promotes team members to share and learn (Fausto etc., 2012), expands the social network, so as to access the external social capital. Consequently, we proposed proposition 2:

The members of heterogeneous entrepreneurial team sort out the external social network, in order to generate more structural holes, is conducive to optimize the path of access to the external social capital.

\section{Social network sharing of the entrepreneurial team} and the activation of external social capital

Shipilov \& Danis (2006) argued that individuals or organizations can expand the interpersonal relationships and social capital by connecting with the internal and external. The members of heterogeneous entrepreneurial team have more extensive social network, but these are scattered and irregular, through sharing social network among members can make these relationship more orderly, thus better mining potential resources. Coleman (1990) pointed out that the higher the degree of interaction between network members, the more opportunities for the exchange of resources and information. In the same way, knowledge sharing among team members is conducive to the activation of human capital, structural capital, etc. (LI li, 2010). Hence through the sharing of social networks can expand relationship and better activate the external social capital. Consequently, we proposed proposition 3 :

Social network sharing is able to develop the potential and available social relationship, thereby activate external social capital of heterogeneous entrepreneurial team.

\section{MethodOLOGY}

\section{A. Case selection}

Because the activation of social capital is a gradual process, so we conducted a longitudinal study on three entrepreneurial teams (Arenius \& Laitinen, 2011). These teams' members all have obvious heterogeneity, so the three sample cases have a certain representation. Furthermore, in order to better explore the feasible activation path of the external social capital, we specifically selected two heterogeneous entrepreneurial teams which are doing the second venture after the entrepreneur failure. After absorbing the previous experience, such entrepreneurial teams will pay more attention to the sharing of the team members' network, the activation and integration of the external social capital. Based on the above consideration, this paper selects three heterogeneous entrepreneurial team: HU-1 (failed in the first venture) and HU-2 (second venture), MC-1 (failed in the first venture) and MC-2 (second venture), and LD (first venture).

\section{B. Data collection}

Research data come from the interview, long-term follow-up observation and other data collection, the outline designed before interview, the object of the interview is the directly responsible person of the case teams. In order to guarantee the objectivity of the data and research reliability, we asked at least two people to participate in each stage of the data collection and analysis. In order to ensure the good validity, the interview is conducted in the form of semi structure. After the interview, if need additional information, we will also communicate with the relevant personnel again through the phone call or another meeting or other modes. This paper uses analytic induction method to analyze the case data, try to seek the universality and gradually stabilize. In accordance with the duration of the entrepreneurial team, the tracking period of the three teams are respectively: HU-2 team for 4 years, MC-2 team for 3 years, LD team for 5 years, the data of HU-1 team and MC-1 team were collected by retrospective method.

\section{Analytical method}

According to the development situation of each team, we divide $\mathrm{HU}-1$ and $\mathrm{MC}-1$ into start-up stage, survival stage and recession stage, $\mathrm{HU}-2$, divide MC-2 and LD into start-up stage and survival stage.

On the basis of the data obtained by field survey, we use the UCINET software of SNA (social network analysis) to quantitatively analyze the case teams, use NETDRAW software to draw out the social network graph of each sample team in every stage of the development, visually analyze the characteristics and evolution rules of the external social capital, and explore the activation mechanism of external social capital of the entrepreneurial team.

\section{DESCRIPTION OF DATA AND ANALYSIS}

\section{A. Network density analysis}

The higher the ratio of network density, the greater the connection density of the network, and the more favorable to gain external social capital.

We analyze the survey data through UCINET, and then acquire the network density values of these entrepreneurial teams at various development stages. The results are shown in Table 1.

TABLE I. NETWORK DENSITY ANALYSIS OF CASE TEAMS IN VARIOUS ENTREPRENEURIAL STAGES

\begin{tabular}{|c|c|c|c|c|}
\hline \multirow{2}{*}{$\begin{array}{c}\text { Network } \\
\text { Density }\end{array}$} & Case & \multicolumn{3}{|c|}{ Various Entrepreneurial Stages } \\
\cline { 2 - 5 } Teams & Start-up & Survival & Recession \\
\hline \multirow{4}{*}{ Density } & HU-1 & 0.0378 & 0.0476 & 0.0475 \\
\cline { 2 - 5 } & HU-2 & 0.0521 & 0.0600 & - \\
\cline { 2 - 5 } & MC-1 & 0.0343 & 0.0471 & 0.0358 \\
\cline { 2 - 5 } & MC-2 & 0.0521 & 0.0600 & - \\
\cline { 2 - 5 } deviation & LD & 0.0490 & 0.0590 & 0.0729 \\
\cline { 2 - 5 } & HU-1 & 0.2538 & 0.2737 & 0.3112 \\
\cline { 2 - 5 } & MU-2 & 0.3356 & 0.3709 & - \\
\cline { 2 - 5 } & MC-1 & 0.2130 & 0.2560 & 0.2690 \\
\cline { 2 - 5 } & MC-2 & 0.2481 & 0.3285 & - \\
\cline { 2 - 5 } & LD & 0.2589 & 0.2878 & 0.3346 \\
\hline
\end{tabular}

As shown in table 1, from the start-up stage to the survival stage, case teams' (first venture or second venture) 
social network densities are all increased, indicating that in the rapid development stage of entrepreneurial team, the network density has an enhanced tendency. According to the in-depth interview, the reason is the main members of these teams intentionally expanded the external social network (such as marketing channels, etc.), and increased the acquisition and usage of the external social resources.

However, from the survival stage to the recession stage, the network densities of HU-1 and MC-1 (failed in the first venture) have not increased, and even decreased. According to in-depth interviews, this situation is mainly due to the poor operating condition, some connections intentionally weakened the contact with the team.

\section{B. Degree centrality analysis}

Degree centrality is the most direct measurement index of depict the node centrality in network analysis, the greater the node degree means the node's degree centrality is higher, the node is more important in the network, and the more conducive to the acquisition of external social capital.

We analyze the survey data through UCINET, and then acquire case entrepreneurial team members' degree centrality values at various development stages. The results are shown in Table 2.

TABLE II. DEGREE CENTRALITY ANALYSIS OF CASE TEAM'S MEMBERS IN VARIOUS ENTREPRENEURIAL STAGES

\begin{tabular}{|c|c|c|c|c|c|c|c|c|c|c|c|c|c|c|c|}
\hline & \multicolumn{5}{|c|}{ Start-up } & \multicolumn{5}{|c|}{ Survival } & \multicolumn{4}{|c|}{ Recession } \\
\hline & & $H U-1$ & $H U-2$ & $M C-1$ & $M C-2$ & $L D$ & $H U-1$ & $H U-2$ & MC-1 & $M C-2$ & $L D$ & $H U-1$ & $H U-2$ & $M C-1$ & $M C-2$ \\
\hline \multirow{5}{*}{ Degree } & M1 & 65 & 90 & 110 & 90 & 93 & 80 & 120 & 153 & 102 & 120 & - & - & 163 & - \\
\hline & $M 2$ & 56 & 95 & 94 & 85 & 93 & 69 & 131 & 122 & 97 & 131 & 80 & - & 132 & - \\
\hline & M3 & 51 & 85 & 88 & 88 & 93 & 68 & 112 & 113 & 96 & 112 & 69 & - & 108 & - \\
\hline & M4 & & & 80 & 150 & & & & 100 & 189 & & & & 107 & - \\
\hline & M5 & & & & 124 & & & & & 138 & & & & & - \\
\hline \multicolumn{2}{|c|}{ Sum } & 386 & 610 & 578 & 698 & 610 & 476 & 778 & 766 & 1396 & 778 & 450 & - & 1002 & - \\
\hline \multicolumn{2}{|c|}{$\begin{array}{c}\text { Network } \\
\text { Centralization }\end{array}$} & $43.94 \%$ & $49.78 \%$ & $48.08 \%$ & $52.59 \%$ & $43.94 \%$ & $62.3 \%$ & $61.26 \%$ & $61.42 \%$ & $67.04 \%$ & $62.3 \%$ & $65.22 \%$ & - & $77.74 \%$ & - \\
\hline
\end{tabular}

As shown in table 2, from the start-up stage to the survival stage, case teams' (first venture or second venture) overall degree centrality and each member's degree centrality are all gradually increased, indicating that in the rapid development stage, the members of entrepreneurial teams are more and more frequently contact with outside network nodes, and the network nodes are more and more diversified, and the heterogeneity of the social networks is also growing. According to the in-depth interviews, the reason is the main members of these teams intentionally expanded new network connections, increase the weak connection, and strengthen their centrality in social network, construct structural holes, thereby increased the acquisition and usage of the external social resources.

On the other side, from the survival stage to the recession stage, although the overall degree centrality and each member's degree centrality of HU-1 and MC-1 (failed in the first venture) are still increased, but the growth rate is very small. According to in-depth interviews, this situation is mainly due to the poor operating condition, some members gradually have the willingness of transformation.

\section{Social network evolution analysis}

In order to more intuitively show the changes and development of the social network of case teams, we combine the survey data and statistical analysis results, drew out case teams' social network diagram at various stages by using NETDRAW software.

Due to the second venture teams' social network evolution rules are similar, so we only present the social network diagram of HU-1 and MC-2 (Figure. 1 and Figure. 2). The social network evolution diagram of LD is shown in Figure 3.
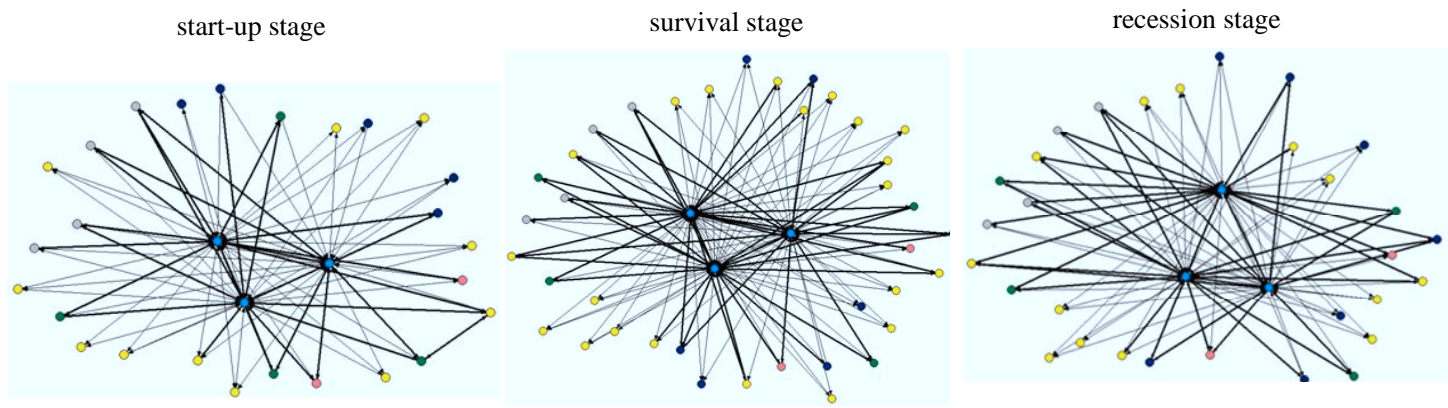

Figure 1. HU-1 team's external social networks at various stages 

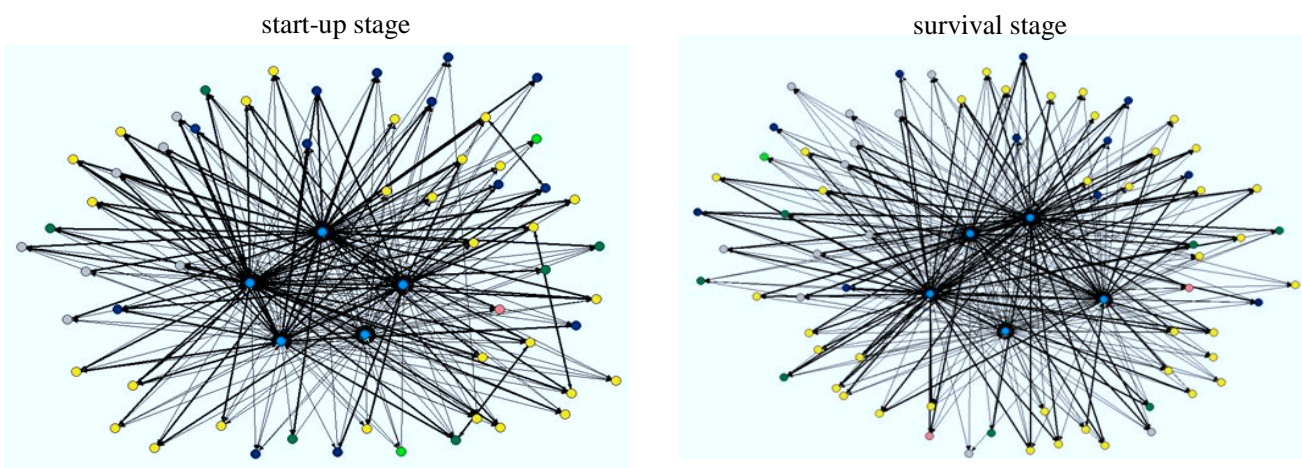

Figure 2. MC-2 team's external social networks at various stages
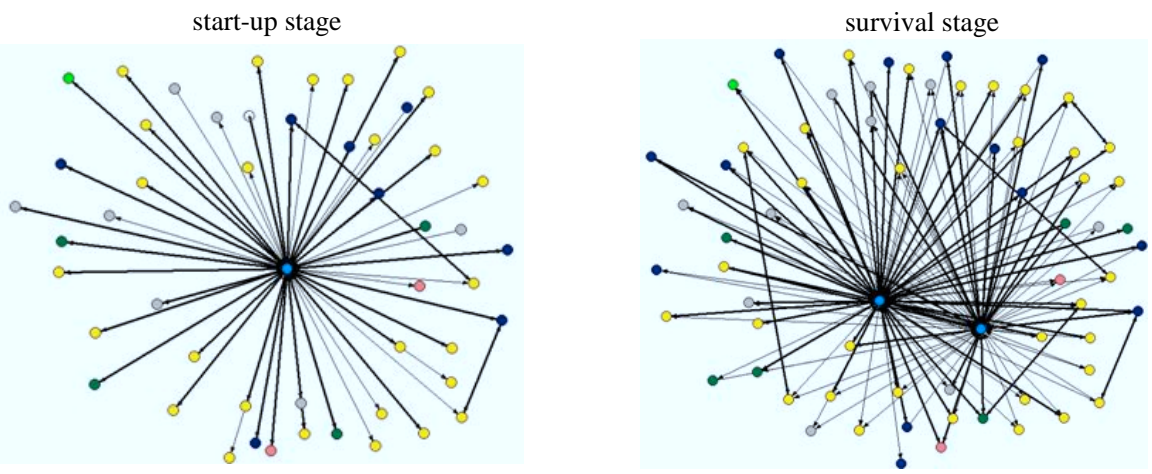

Figure 3. LD team's external social networks at various stages

First of all, the Figure 1-3 indicate that whether the team is first venture or second venture, from the start-up stage to the survival stage, its external social network all gradually becomes intensive, the number of external connections and relationships increased significantly. In contrast, from the survival stage to the recession stage, the network density of the entrepreneurial team not only did not increase, but appeared to reduce.

Secondly, the social network diagram shows that in the start-up stage, team members use most of the relationship of high strength and high degree of accessibility. With the development of entrepreneurial activity, there are more and more external strong ties (thick lines), the heterogeneity of external relationship nodes increases, and the core members' network centralities also increase. This shows that the strength of team members' external social network increased, and they expanded and used more and more strong and heterogeneous relationship.

Thirdly, as shown in the Figure 1-3, in the start-up stage, many external nodes are exclusive by certain member. With the development of entrepreneurial activity, members start to share social network, external social network nodes are connected with more than one core member. In addition, the members of heterogeneous entrepreneurial team possess more structural holes, and social network sharing can generate more new structural holes, such changes can help the entrepreneurial team more effective access to and use the heterogeneous social resources.

\section{CONCLUSIONS}

\section{A. The discussion of the results}

1) The entrepreneurial team not only use strong ties to activate the external social capital, sometimes the weak ties also play a great role.

At the start-up stage, team members' strong ties are more effective to activate the external social capital than weak ties. But the external social capital that strong ties can provide is limited, at this time the weak ties are more conducive to expand the external social networks, and activate the external social capital.

2) The members of heterogeneous entrepreneurial team possess more structural holes, is conducive to obtain and integrate external social resources.

According to the literature research and our research, we found sharing social network among members can generate new structural holes, and help team members to occupy a favorable position in the social network, acquire and use more external social capital.

3) Social network sharing of team members can develop more potential and useful social relations, activate the external social capital of entrepreneurial team.

Heterogeneous entrepreneurial teams' members have more heterogeneous networks, but dispersedly expand network relations is neither efficiency nor effective. Through the entrepreneurial team members' social network sharing can more scientifically explore potential 
opportunities and resources, let the activation of external social capital activation more directivity.

\section{B. The discussion of activation path}

Although there are more and more entrepreneurial team in recent years, but the success rate and duration are not ideal. To a large extent, the activation degree of external social capital determines the entrepreneurial teams' survival and development. According to our research, we propose the following suggestions for the heterogeneous entrepreneurial team (Figure. 4).

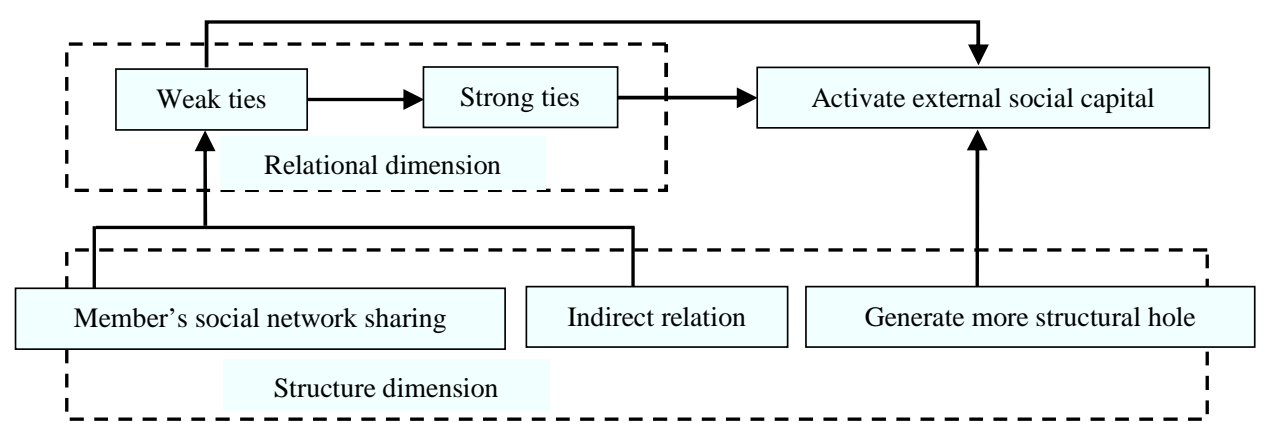

Figure 4. Activation path of external social capital of heterogeneous entrepreneurial team

1) Strengthen the strong ties originally possessed by entrepreneurial teams' mambers.

In the start-up stage, all entrepreneurial team will inevitably encounter the problem of the shortage of resources, the original social relations such as parents, relatives and friends become the first path for the activation of external social capital (Arregle, Batjargal, Hitt, et al., 2015).

2) Extend more weak ties, and convert some of them to strong ties selectively.

Through the sharing of team members' heterogeneous network to expand the entrepreneurial teams' overall external connections, through the bridge connections (middleman) to expand more potential and useful social relations, and then select the key relations to transform into strong ties.

3) Generate more structural holes to occupy a favorable position in the network.

People are more willing to allocate resources according to the relationships' nature and distance. So possessing more structural holes can make team members to occupy a favorable position in the social network, facilitate the discovery and activation of external social capital.

In summary, entrepreneurial team should initiatively activate the external social capital, through the integrated use of strong ties and weak ties, direct and indirect relations to obtain more abundant and heterogeneous resources, to increase the success rate of entrepreneurship.

\section{ACKNOWLEDGMENT}

This work was supported by Zhejiang Provincial Natural Science Foundation of China [grant number: LQ13G020015], the Postgraduate Teaching Reform Project for the Provincial Key Subjects 'Enterprise Management' [grant number: qygljg201404] and the Educational Reform Research Project of Zhejiang SciTech University [grant number: jgel201425].

\section{REFERENCES}

[1] D.H.Francis, W.R.Sandberg, "Friendship within entrepreneurial teams and it association with team and performance", Entrepreneurship: Theory and Practice, vol.25, May. 2000, pp. 525.

[2] M.Granovetter, "The strength of weak ties". American Journal of Sociology, vol.78, Jun. 1973, pp. 1360-1380.

[3] Zhou Dongmei, Lu Ruoyu, "Searching resource based on choice of strong ties and weak ties in entrepreneurship network", Management of Innovation and Entrepreneurship, Jan. 2011, pp. 113.

[4] Bian Yanjie, "A social network model of the job search process: testing a relational effect hypothesis", Social, vol.32, Mar. 2012, pp. 24-37.

[5] Zuo Jingjing, Xie Jinyu, Sun Shaorong, "Social network structure and social network resource-based on questionnaire survey of 270 sci-tech university student entrepreneurs", Human Resources Development of China, May. 2013, pp. 6-15.

[6] R.Burt, "Structural holes: the social structure of competition", Harvard University Press, 1992.

[7] D.V.Fausto, Jens Hemphälä, Mats Magnusson, Daniele Mascia, "Exploring theory of structural holes in learning: an empirical study of Swedish pharmacies", Journal of Knowledge Management, Mar. 2012, pp. 257-276.

[8] A.Shipilov, W.Danis, "TMG Social Capital, strategic choice and firm performance", European Management Journal, vol.24, Jan. 2006, pp. 16-27.

[9] J.S.Coleman, "Foundations of social theory", Cambridge: Harvard University Press, 1990.

[10] B.Batjargal, M.Hitt, A.Tsui, et al., "Institutional polycentrism, entrepreneurs' social networks, and new venture growth, Academy of Management Journal, vol.56, Apr. 2013, pp. 1024-1049.

[11] P.Arenius, K.Laitinen, "Entrepreneurial teams and the evolution of networks: a longitudinal study", The International Journal of Entrepreneurship and Innovation, vol.12, Apr. 2011, pp. 239-247.

[12] J.Arregle, B.Batjargal, M.Hitt, et al., "Family ties in entrepreneurs' social networks and new venture growth", Entrepreneurship Theory and Practice, vol.39, Mar. 2015, pp. 313-344. 